\title{
Resolving Radiological Waste Classification and Release Issues Using Material Process Information and Simple Measurements and Models
}

by

R. C. Hochel

Westinghouse Savannah River Company

Savannah River Site

Aiken, South Carolina 29808

DOE Contract No. DE-AC09-96SR18500

This paper was prepared in connection with work done under the above contract number with the U.S.

Department of Energy. By acceptance of this paper, the publisher and/or recipient acknowledges the U.S. Government's right to retain a nonexclusive, royalty-free license in and to any copyright covering this paper, along with the right to reproduce and to authorize others to reproduce all or part of the copyrighted paper.

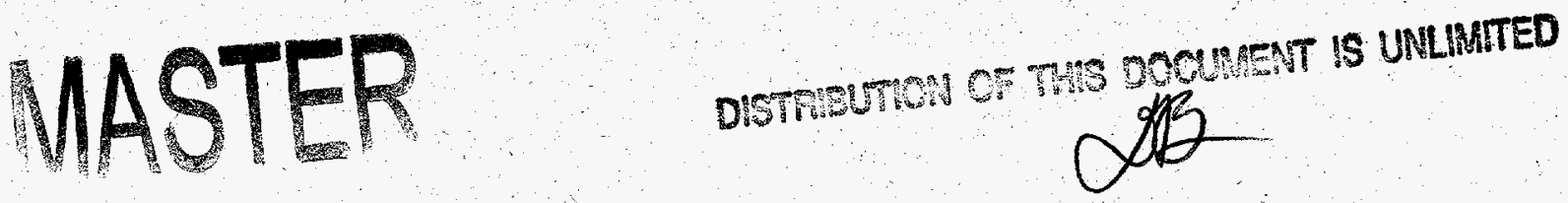




\section{DISCLAIMER}

This report was prepared as an account of work sponsored by an agency of the United States Government. Neither the United States Government nor any agency thereof, nor any of their employees, makes any warranty, express or implied, or assumes any legal liability or responsibility for the accuracy, completeness, or usefulness of any information, apparatus, product, or process disclosed, or represents that its use would not infringe privately owned rights. Reference herein to any specific commercial product, process, or service by trade name, trademark, manufacturer, or otherwise does not necessarily constitute or imply its endorsement, recommendation, or favoring by the United States Government or any agency thereof. The views and opinions of authors expressed herein do not necessarily state or reflect those of the United States Government or any agency thereof.

This report has been reproduced directly from the best available copy.

Available to DOE and DOE contractors from the Office of Scientific and Technical Information, P.O. Box 62, Oak Ridge, TN 37831; prices available from (615) 576-8401.

Available to the public from the National Technical Information Service, U.S. Department of Commerce, 5285 Port Royal Road, Springfield, VA 22161. 


\section{DISCLAIMER}

Portions of this document may be illegible electronic image products. Images are produced from the best available original document. 
KEY WORDS:

Detection Limits

Radionuclide

Radioactive Waste Disposal

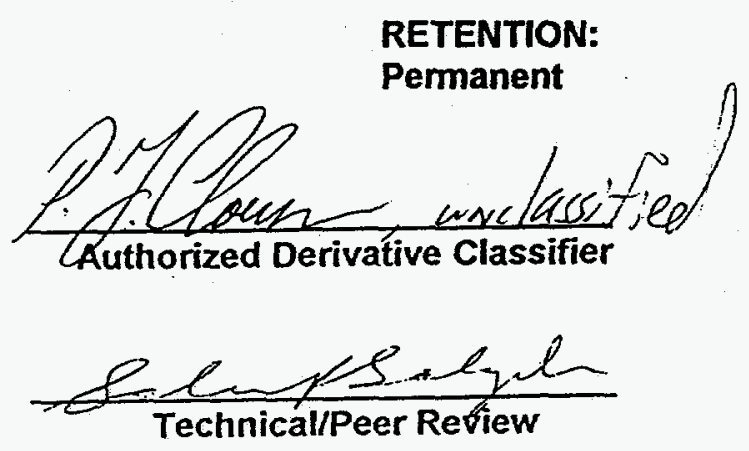

\title{
Resolving Radiological Waste Classification and Release Issues Using Material Process Information and Simple Measurements and Models (U)
}

By

\author{
R. C. Hochel
}

November 17, 1997

This report was prepared as an account of work sponsored by an agency of the United States Government. Neither the United States Government nor any agency thereof, nor any of their employees, makes any warranty, express or implied, or assumes any legal liability or responsibility for the accuracy, completeness, or usefulness of any information, apparatus, product, or process disclosed, or represents that its use would not infringe privately owned rights: Reference herein to any specific commercial product, process, or service by trade name, trademark, manufacturer, or otherwise does not necessarily constitute or imply its endorsement, recommendation, or favoring by United States Government or any agency thereof. The views and opinions of the author expressed herein do not necessarily state or reflect those of the United States Government or any agency thereof. 
WSRC-TR-97-00372

Revision 0

\section{Executive SUMMARY}

Cost effective disposal of potentially contaminated waste at SRS suffers from an inability to unambiguously distinguish among transuranic waste, low-level waste, and unconditional-release material. Disposal of uncontaminated waste improperly classified as low-level waste is about ten times more expensive, and if it's called TRU waste it's about a hundred times more. The technical problems here are not unlike those successfully resolved commercially. Application of that technology at SRS could reduce the uncertainty of waste classification and reduce disposal costs by at least $\$ 2,000,000$ per year.

Most savings would come from unconditional release to off-site (commercial or Three Rivers) burial of most LLW now going to the expensive E-Area vaults. This is the advice from a study by site and commercial waste experts ${ }^{1}$ which says the impediments to this cheaper disposal at SRS are institutional, not regulatory. This refers mostly to the site's lack of new or available measurement equipment and methods specifically applied to the challenge posed by certain unique requirements for DOE-regulated wastes. But suitable ways of meeting this challenge are available and used routinely for commercial waste. Implementation at SRS, aside from modest capital expenditures, is largely a matter of establishing appropriate procedures, equipment, and measurement responsibilities for the proper characterization and classification of a small number of large-volume wastes. The necessary technical and measurement expertise to do this need not come from resource-strapped radiological control groups; it is minimal and available within SRTC. But mustering of other necessary financial and implementation resources to realize the huge cost savings can come only through interdepartmental management support.

What makes this possible is that in waste classification, as opposed to analysis, applications, the proper question is not "How much activity is present?" but rather "Is the activity less than a certain regulatory limit?" This distinction is enormous from the perspective of measurement certainty and adequacy. By recognizing this distinction and applying it wisely, many potentially contaminated SRS materials can be verified, not merely assigned, for disposal decisions. The amount of material being classified too conservatively can be reduced by $30-60 \%{ }^{1}$ with corresponding reductions in cost.

Fulfillment of regulatory requirements for characterization and classification of commercial radioactive waste is accomplished with a gamma measurement system such as the Box Waste Monitor to infer package activity from dose-to-curie correlations predicted from a computer model such as MicroShield ${ }^{\top M}$. Similarly, using certain unique attributes of SRS nuclear materials along with process information in combination with some simple radiological measurements, the gamma-ray detection response of many site waste items can be easily modeled to resolve common waste characterization and release issues - even for many potential alpha-contaminated wastes - with accuracies sufficient to answer the many practical "what if" questions that arise in measuring radionuclides. 
WSRC-TR-97-00372

Revision 0

\section{INTRODUCTION}

Measurements of the amount of radioactivity contained in vessels or packages typically encountered in waste situations are usually very different from ones in the laboratory. The amount of radiation flux reaching any point in space, where an appropriate detector may be positioned to respond, depends on many variables. These include: type of radiation and energy, source distance, source size and shape, the source matrix, source distribution, and shielding. In the laboratory all of these variables are fixed or minimized, so that once calibrated, reproducible and accurate measurements can be made routinely on appropriately prepared samples.

But consider the practical case of a closed waste package of, say, a modest $0.15 \mathrm{~m}^{3}$ (21-inch cubical) box. The radioactive material present might be in one or many clumps anywhere in the box, or it might be distributed nearly uniformly in the matrix material. For a single-centered measurement point 30 centimeters from the surface of the box, the variation in gamma flux could be nearly an order of magnitude due to spatial uncertainty alone. Also, the bulk density and elemental constituents of the matrix material could vary widely. This affects the intensities of escaping gamma rays at the detector as will any other materials in between. Given a limited number of gamma detector measurements, the challenge typically is to identify the radionuclides and their activity levels in the box.

To the health physicist charged with protecting personnel from the radiation hazard such a box might present, the question is usually the inverse: given the activities in a box of radionuclides, what is the energy fluence and related dose at some point in space under certain shielding conditions? The physics affecting both dose and analytical flux measurements are well understood from first principles and the variables involved, and can be found in text books ${ }^{2,3}$. Happily, computer codes better than the originally developed ISOSHLD ${ }^{4}$ mainframe program are available to simplify this important but burdensome calculational task. One code enjoying wide use in nuclear industry is MicroShield $4.21^{\text {tw }}$, a popular user-friendly PC adaptation.

Details of MicroShield, its use, and a series of validation measurements against NISTtraceable standards are presented in the appendix of this report. But first the questions of how the combination of modeling, process knowledge, and measurement information could be used to defensibly distinguish and classify materials or waste from the site's two large-volume TRU and LLW streams are addressed.

\section{RESOLVING MATERIAL CLASSIFICATION ISSUES}

There are several important radiological classification issues associated with most materials that are radioactive, or potentially contaminated. How a material is classified determines how it must be disposed of, and poses very significant cost differences for those who must deal with it. The classifications loosely and broadly are 1) Transuranic (TRU) Waste:100 nCi/g or more of Np, Pu, Am, etc., 2) Low-Level Waste (LLW): any 
activity above that of naturally occurring radioactive materials and which is not in another classification ${ }^{6}$, and 3) Unconditional-Release Material (URM): material below surface contamination limits of $500 \mathrm{dpm} / 100 \mathrm{~cm}^{2}$ of $\alpha$ or $5,000 \mathrm{dpm} / 100 \mathrm{~cm}^{2}$ of $\beta-\gamma$. URM are those materials that can be released from administrative control after confirming that the residual radioactive material meets the guidelines in DOE Order $5400.5^{7}$ It is possible for URM and LLW to have equal levels of contamination. But if a material is declared URM, it is, by definition, not LLW; however, it may still be radioactive. Typical disposal costs decrease by roughly an order of magnitude each, for the three classifications with TRU being the highest. As a result of the costs involved, disposing of materials at the lowest defensible classification is extremely important.

The SRS surface contamination limits for alpha are set a factor of five higher than those in DOE guidance for 5400.5 . Also, both sets have even lower limits (20\% or less) for removable contamination. Such criteria differences are best avoided for URM decisions by prior checks (smears and surveys) to assure no removable contamination, and that any alpha correlates well with more easily measurable gamma activity (process knowledge).

Increasingly, nuclear materials measurement experts are called on to supply the justification for classification decisions. In most cases, all that is known is where the material comes from; size and weight of the packaged material; the gamma measurement distance; and a maximum-dose rate reading, provided for radiological safety. Knowing the origin of the material often can be used to infer the radionuclides present and their relative activity levels, but this is uncertain, as is the physical distribution of the isotopes in the package and the matrix or shielding materials which happen to be present. The effects of all these uncertainties can be reasoned in a qualitative sense, but they need to be quantified or at least bounded for radiological classification purposes.

To reach defensible conclusions about the contents of the material and its proper classification, one must know how various parameters affect gamma fluxes, and something of the response of the detector to the gamma radiation. An invaluable aid is MicroShield which can provide all the needed information about parametric effects, so the measurement expert can concentrate on an appropriate detector and measurement precautions. Sometimes the package dose rate alone may be enough to support a classification, and is the basis of the dose-to-curie methods used in many waste characterization applications. However, many materials requiring disposal present no detectable dose; yet they may be potentially contaminated and must be classified. This calls for much more sensitive and refined measurements than just dose.

A good yet simple choice for classifying many different materials is the box waste monitor (BWM), so named because it is designed to count boxed wastes placed inside the device. Four or six plastic scintillation detectors normally are used in a monitor, depending on the size and shape of the materials to be checked. These typically have constant detection efficiencies of $5-10 \%$ for nearly all gamma rays likely to be 
encountered from wastes, and they can be made in very large sizes of $5000 \mathrm{~cm}^{2}$ or mole. With such a device and the aid of Table 1 below, it is possible to show how easily some classification issues can be conservatively and defensibly decided.

Table 1 lists the gamma fluxes predicted from hypothetical loadings of one curie of either Am-241, Cs-137, or Co-60 under several different distribution and shielding extremes. Cases are for air, job-control (JC) waste, aluminum, and iron shields as either a point source or a uniformly distributed source in a $0.15 \mathrm{~m}^{3}$ cubical cardboard box. The job-control waste shield is an assumed matrix composition. It simulates light materials like plastic, paper, glassware, and protective clothing, which are continually generated on jobs involving radioactive contamination and materials. Its homogeneous composition is assumed to be $30 \%$ each of paper, polyethylene, and polyvinylchloride, and $10 \%$ silica with a density of $0.2 \mathrm{~g} / \mathrm{cc}$. It is an easy MicroShield exercise to show that bulk density of the material, rather than composition, is the most important parameter to be considered. This is also the reason why the popular $\mathrm{Q}^{2}$ and ISOCS systems ${ }^{8}$, which use no transmission source to correct for attenuation effects, are enjoying expanded use in waste characterization and analysis applications. For each case in the table, the measurement point is $5 \mathrm{~cm}$ from the box surface. The point source in air shield represents the maximum flux condition for comparison. The iron and aluminum shield thicknesses chosen are judged to represent the maximum cladding on typical pieces of equipment likely in wastes.

Table 1. Predicted Gamma Fluxes for Extremes in Source Distributions and Shields

\begin{tabular}{|c|c|c|c|c|c|c|}
\hline (1) & (n) & 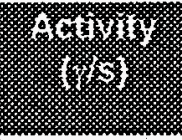 & 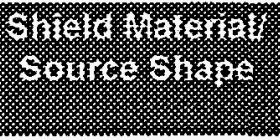 & 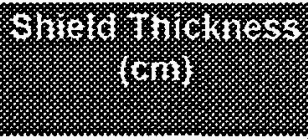 & 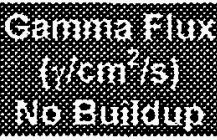 & 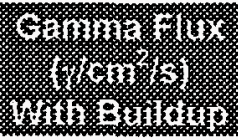 \\
\hline \multirow[t]{5}{*}{ Am-241 } & 60 & $1.328 \mathrm{E}+10$ & Air/Point & $3.175 E+01$ & $1.047 \mathrm{E}+06$ & $1.061 E+06$ \\
\hline & & & JC/Distributed & $5.334 E+01$ & $5.408 E+05$ & $1.674 \mathrm{E}+06$ \\
\hline & & & JC/Point & $3.175 \mathrm{E}+01$ & $3.076 \mathrm{E}+05$ & $1.847 E+06$ \\
\hline & & & Aluminum/Point & $1.905 E+00$ & $2.859 E+05$ & $1.832 E+06$ \\
\hline & & & Iron/Point & $6.350 \mathrm{E}-01$ & $3.294 E+03$ & $1.704 E+05$ \\
\hline \multirow[t]{5}{*}{ Cs-137 } & 662 & $3.190 \mathrm{E}+10$ & Air/Point & $3.175 E+01$ & $2.491 E+06$ & $2.50 E+06$ \\
\hline & & & JC/Distributed & $5.334 E+01$ & $1.963 E+06$ & $2.52 E+06$ \\
\hline & & & JC/Point & $3.175 E+01$ & $1.610 E+06$ & $2.35 E+06$ \\
\hline & & & Aluminum/Point & $1.905 \mathrm{E}+00$ & $1.700 E+06$ & $2.37 E+06$ \\
\hline & & & Iron/Point & $6.350 \mathrm{E}-01$ & $1.734 \mathrm{E}+06$ & $2.38 E+06$ \\
\hline \multirow[t]{5}{*}{$C 0-60$} & 1332 & $3.700 E+10$ & Air/Point & $3.175 E+01$ & $2.929 E+06$ & $2.933 E+06$ \\
\hline & & & JC/Distributed & $5.334 E+01$ & $2.500 E+06$ & $2.917 E+06$ \\
\hline & & & JC/Point & $3.175 \mathrm{E}+01$ & $2.145 E+06$ & $2.691 E+06$ \\
\hline & & & Aluminum/Point & $1.905 \mathrm{E}+00$ & $2.142 E+06$ & $2.690 \mathrm{E}+06$ \\
\hline & & & Iron/Point & $6.350 \mathrm{E}-01$ & $2.141 E+06$ & $2.690 E+06$ \\
\hline
\end{tabular}

The numbers in Table 1 are taken directly from individual MicroShield case analyses and reveal some facts which may not be intuitive. For instance, the flux differences between a uniformly distributed source compared to the opposite extreme of an 
WSRC-TR-97-00372

Revision 0

equivalent point source in the center of the box is fairly small for typical gamma-ray energies. This is the result of choosing an axially-symmetric measurement point which minimizes spatial effects. Also, when buildup is considered, the scattered flux largely compensates for the attenuation from the different shields and can actually be larger than that of an unshielded point source. These two facts mean that under proper measurement conditions uncertainties from parametric effects become manageably small.

\section{AN SRS EXAMPLE OF DISTINGUISHING MATERIALS FOR UNCONDITIONAL RELEASE FROM LLW}

An important waste classification issue, particularly in decontamination and decommissioning operations, is being able to show whether materials are suitable for unconditional release, or if they must be disposed of, more expensively, as LLW. To protect public health, URM is subjected to very careful measurements and scrutiny. Materials are usually evaluated on a case-by-case basis to assure they meet the applicable criteria for release. The criteria, however, depend on the nature of the potential contamination as well as how it is distributed in the material. This has caused much confusion and needlessly created a virtual moratorium on the release of nearly all potentially contaminated materials.

Materials with residual radioactivity in mass or volume (bulk radioactivity) have different authorized limits for release than do materials with only surface contamination. However, authorized limits for surface contamination are the only ones that are readily amenable to direct verification by field measurements. As a result, surface limits have become the de facto criteria for nearly all URM classifications. This is viewed as an acceptably conservative practice and survey protocols for bulk radioactive material, in lieu of authorized limits, may be derived and approved by the DOE Operations Office (see reference 7). Such special limits have been used at SRS in several instances, particularly in the release of used railroad crossties for public sale ${ }^{9}$.

Release of the crossties involved an activity measurement for Cs-137, a nearly universal indicator of fission product contamination, compared to the $5000 \mathrm{dpm} / 100$ $\mathrm{cm}^{2}$ total $\beta-\gamma$ surface contamination limit for URM. Although potential activity on the ties would not be only on the surface and could be partially removable, the $5000 \mathrm{dpm} / 100$ $\mathrm{cm}^{2}$ limit was considered acceptable. Substituting surface limits is appropriate and conservative for almost all materials because it assumes that all the activity either in or on an object is distributed only on the surface where it would pose the greatest contamination or dose hazard. Also, contamination on ties would likely result from leaks involving shipments of irradiated reactor fuels and targets, and could contain a small amount of $\alpha$-contamination. However, specific $\alpha$-monitoring was deemed unnecessary, as it is impractical and alpha is known to comprise only a small fraction of the fission product contamination. The ties were scanned whole using a four-detector monitor like the BWM in conjunction with a conveyor belt which could scan ties at a rate of one per minute. 
Over half of SRS materials, if contaminated, can be expected to show fission product characteristics. Exceptions would be materials from the few areas or instances where single, separated or unirradiated activities are processed. Questionable materials can be gamma scanned or clarified by liquid scintillation spectroscopy, versus simple counting, of the smears required prior to movement or screening of potentially contaminated materials. Spectroscopy gives an energy display of alpha and beta emissions which often is sufficient to identify the dominant radionuclide contaminants, and is an increasingly popular feature of modern liquid scintillation counters. Also, positive smears would also signal removable contamination, which might suggest decontamination or rejection from URM consideration. Once these simple precautions are taken, a BWM approach can be used to quickly distinguish URM from LLW for many materials.

The fission product gamma-ray spectrum is mostly due to Cs-137, which constitutes about a third of the total activity in the typical aged material at SRS and can be easily verified in any case. Therefore, to remain under the $5000 \mathrm{dpm} / 100 \mathrm{~cm}^{2}$ total $\beta-\gamma$ surface contamination limit for URM, items must be less than about $1670 \mathrm{dpm} / 100 \mathrm{~cm}^{2}$ in Cs137. If the URM was again a $0.15 \mathrm{~m}^{3}$ box with a surface area of $1.71 \times 10^{4} \mathrm{~cm}^{2}$, it could contain up to about $0.13 \mu \mathrm{Ci}$ of Cs-137. [This is again conservative as the surface areas of all materials in the box would far exceed that box's six sides; also, boxed URM will be land-fill disposed, not released to the public.]

$$
\left[1.67 \times 10^{3} \mathrm{dpm} /\left(100 \mathrm{~cm}^{2}\right)\right]\left[1.71 \times 10^{4} \mathrm{~cm}^{2}\right] /\left[2.22 \times 10^{6} \mathrm{dpm} / \mu \mathrm{Ci}\right]=1.29 \times 10^{-1} \mu \mathrm{Ci}
$$

Referring to the last column of Table 1, and assuming maximum shielding (JC/Point) conditions, conservative and defensible conclusions can be reached as to a material's classification. Assuming the activity is all at the center of the box under minimum flux (worst case) conditions the flux with buildup at $5 \mathrm{~cm}$ from the sides of the box would be

$$
\left[1.29 \times 10^{-7} \mathrm{Cij}\right]\left[2.35 \times 10^{6} \gamma /\left(\mathrm{cm}^{2}-\mathrm{s}-\mathrm{Ci}\right)\right]=3.03 \times 10^{-1} \gamma /\left(\mathrm{cm}^{2}-\mathrm{s}\right)
$$

A BWM of $5000 \mathrm{~cm}^{2}$, assuming a $10 \%$ detection efficiency for the scattered and unscattered $662-\mathrm{keV}$ gamma rays, would count at about $9100 \mathrm{cpm}$ for such a box.

$$
\left[3.03 \times 10^{-1} \mathrm{\gamma} /\left(\mathrm{cm}^{2}-\mathrm{s}\right)\right]\left[5 \times 10^{3} \mathrm{~cm}^{2}\right]\left[1 \times 10^{-1} \mathrm{c} / \gamma\right][60 \mathrm{~s} / \mathrm{m}]=9.10 \times 10^{3} \mathrm{c} / \mathrm{m}
$$

This is well above a typical one-minute BWM detection limit of $2000 \mathrm{cpm}$, so screening such materials to URM levels would be relatively easy.

Licensed landfill disposal of such materials, when they are below certain de minimus levels, is a common commercial practice. At SRS there are institutional impediments to this, but if on-site burial (slit trenches, Three Rivers land fill, or other space) becomes available, waste experts believe that much or most LLW could be so disposed. 
Also, there are numerous relatively flat materials at SRS like sheet metals, pipes, scaffolding, and electronic equipment such as computers that have good salvage or reuse value if they can be classified as URM. These materials would be good candidates for conveyor monitors like the one in reference 9 . These monitors have entrance and exit openings and count materials as they pass through the detector tunnel at a constant speed, typically a few centimeters per second. While fewer detectors reduces sensitivity, detector spacing around the object is much closer together and the resultant flux increase usually more than makes up for the difference. So these materials are also easily doable.

With metals comes the additional concern of materials that may have been activated. Co-60 is the dominant neutron activation product in many aged metals subjected to irradiation in and around nuclear reactors. ${ }^{10}$ Activated stainless steel contains significant amounts of Co-60, which Table 1 shows can be detected even more easily than Cs-137 contamination. This will preclude most irradiated metals from being accidentally disposed of incorrectly. Aluminum and carbon steels are an exception. If irradiated, they contain no telltale Co-60. Instead, a few years after irradiation, the dominant activity present will be Fe-55, even in aluminum. A BWM is insensitive to this activity, but Fe-55 would be readily detectable by liquid scintillation of smears from suspect metals. Carbon steels and aluminum quickly form an oxide surface layer which is easily counted for low energy $x$-rays or sampled with smears.

\section{AN SRS EXAMPLE OF DISTINGUISHING TRU FROM LLW}

As another real SRS example, consider a box of JC-waste generated at the FB-Line facility. Waste characterization data for FB-Line indicates weapons-grade plutonium as the dominant radionuclide distribution in the facility. The fact that plutonium decays with almost no photon emission would seem to preclude using a BWM. But Am-241, a prominent $60 \mathrm{keV}$ gamma-emitter, contributes a fair portion of the total activity in most FB-Line materials. For old material (such as the more than 35,000 drums of stored, suspect TRU waste at SRS which will someday have to be screened for proper disposal) with a decay time of at least ten years from either genesis or any separation processing, the minimum $60-\mathrm{keV}$ photon emission will be about $3.9 \%$ of the total TRU activity. ${ }^{*}$

The key classification issue here is whether or not boxes (or drums) of such waste can be measured in a BWM to segregate TRU from LLW. From the sixth column of Table 1 for Am-241, the unscattered flux under the maximum shielding case (Iron/Point) is $3.29 \times 10^{3}$. The fluxes with buildup are not appropriate to use here because of the low $60-\mathrm{keV}$ gamma energy involved. Most $60-\mathrm{keV}$ scattered gammas would not have sufficient energy to be detected.

*(Note: This excludes Pu-241, which is not a TRU isotope. Younger materials will contain significantly less Am-241, so an analytical determination from smear samples must be made prior to any screening measurements on fresher materials.) 
The question of TRU vs. LLW now becomes one of showing if the Am-241 concentration is less than $3.9 \mathrm{nCi} / \mathrm{g} \mathrm{(3.9 \%}$ of the $100 \mathrm{nCi} / \mathrm{g}$ TRU limit) in the extreme case (Iron/Point). If a box weighs, say, 10 kilograms, then the Am-241 activity in the box would need to be below $39 \mu \mathrm{Ci}$. A box at this level in a 5000- $\mathrm{cm}^{2}$ BWM monitor with a detection efficiency of $5 \%$ for the 60-kev gamma rays, would count about 1920 counts per minute above background.

$$
\left[3.29 \times 10^{3} \gamma /\left(\mathrm{cm}^{2}-\mathrm{s}-\mathrm{Ci}\right)\right][39 \mu \mathrm{Ci}]\left[5 \times 10^{3} \mathrm{~cm}^{2}\right]\left[5 \times 10^{-2} \mathrm{c} / \gamma\right][60 \mathrm{~s} / \mathrm{m}]=1.92 \times 10^{3} \mathrm{c} / \mathrm{m}
$$

This is just at the typical one-minute BWM detection limit for a device of this size. Depending on the degree of conservatism desired, count times of just a few minutes would be needed to assure that these materials could be correctly classified. Similar calculations show that 55-gallon drums, using a larger monitor, are also doable at this level. For the much lighter JC-waste from FB-Line, packages as young as one-month could be similarly screened.

\section{CONCLUSIONS}

The above discussions and examples clearly show, that despite many unknowns presented by potentially contaminated materials, simple gamma measurements such as the BWM in conjunction with computer modeling can provide sound defensible data and documentation necessary for proper classification and disposal. The computer code MicroShield is a preferred choice for such modeling because of its success in similar applications in the commercial sector and its ubiquitous use in nuclear science.

Such approaches are common practice in the commercial sector, and need to be implemented at SRS. Current site practices as applied to material disposal at SRS, when compared to commercial ones, are cumbersome, and need to be revised into more flexible procedures. This was, perhaps, the most important finding of the Savannah River Site Low-Level Waste Treatment and Disposal Flowsheet task team of experts charged with looking for cost effective solutions to SRS waste problems (see reference 1). With the potential for annual savings of millions of dollars, better, faster, and cheaper ways to deal with our wastes must be found.

In the face of shrinking budgets and staff, this can only be done by working smarter. To do this, existing skills and resources beyond radiological protection groups need to be unleashed. More sharing of measurement responsibilities needs to be entrusted to the waste generators and material custodians. These are the people who best know the history of materials, and how to handle, measure, and dispose of them. Empowering them to do this is mostly a matter of procedural changes and some necessary training to take over certain measurement functions now performed only by radiological protection personnel. This is precisely the intent and purpose of the site's new Advanced Radiological Worker Training program, which could be easily expanded to include the type functions outlined here. 
APPENDIX: MicroShield 4.21 Use and Validation Testing

\section{PREFACE}

Information in this appendix is provided to illustrate the calculational methodology of MicroShield 4.21 for comparison to other shielding/dose models that exist primarily for radiological control purposes. Although MicroShield provides dose information which may be useful for benchmarking against other codes, it is not intended as a replacement for any health physics application. Instead, only its analytical flux predictions are of importance and concern here, and these were specifically tested against some suitable NIST-traceable standards of varied geometries. Results here are intended as a technical documentation of the code's abilities in waste classification and characterization applications. Specific questions about its use or other technical details and documentation should be referred to the author.

\section{MICROSHIELD BASICS}

Older versions of MicroShield made many improvements over its ISOSHLD predecessor, but the calculational approach of point kernel integration is the same. This solves, either analytically or numerically, the flux equation:

$$
\varphi=\int_{V} S_{v}\left(B e^{-b} / 4 \pi \rho^{2}\right) d V
$$

where :

$$
\begin{aligned}
& \varphi=\text { flux in } \gamma /\left(\mathrm{cm}^{2}-\mathrm{s}\right) \\
& S_{\mathrm{v}}=\text { unit volume source strength in } \gamma /\left(\mathrm{cm}^{3}-\mathrm{s}\right) \\
& B=\text { Buildup Factor } \\
& \mathrm{b}=\sum \mu_{\mathrm{i}} \tau_{\mathrm{i}} \\
& \rho=\text { distance to the dose point from any point kernel in the source in } \mathrm{cm}
\end{aligned}
$$

The $\mu_{\mathrm{i}} \tau_{1}$ terms are linear attenuation coefficient and line-of-sight thickness products from each kernel in the source through each shield or absorption medium present to the dose (detector) point.

Two conditions are necessary to solve this flux equation: 1) the source strength, $S_{v}$, must be uniformly distributed in the source volume, so that it may be removed from the integral sign; and 2) each kernel distance, $\rho$, must be analytically expressible over the entire source volume. The first condition is usually assumed to be met for reasonably homogeneous source materials, but this can be checked. Although solid wastes are seldom homogeneous, practice is to treat them as such, and then examine the effects of the opposite. The second condition requires limiting source geometries to regular shapes: points, lines, rectangular areas and volumes, disks, spheres, right and annular cylinders, truncated cones, and infinite slabs and planes. 
When these conditions cannot be met, more complex and sophisticated codes such as MCNP ${ }^{11}$ can be employed. These, however, are not simple to use or familiar to most health physics or gamma measurement specialists. Experience shows that such exceptional cases are infrequent, or that they can be successfully treated, or at least bounded, by the simpler MicroShield.

\section{BASIS FOR USING MICROSHIELD FOR ANALYTICAL APPLICATIONS}

Historically, MicroShield has been used primarily for computing dose rates expected from storage tanks or contaminated items under various shielding conditions. The normal outputs from the code are exposure rates (mR/hr) computed with and without buildup. Buildup is an empirical measure of the additional flux or dose produced mostly from gamma rays Compton-scattered back into the detector from surrounding materials. It is reported so that the user can see when the empirical buildup contribution is large and possibly suspect. The user typically specifies as inputs the case geometry, source strength, shield compositions, and a dose point. Source strengths may be entered as nuclide concentrations or as individual photon energies and activities, and shields may be of any element or chemical composition and density.

MicroShield has been compared successfully to several ANSI ${ }^{12}$ and $E S I S^{13}$ reference problems. These comparisons are reassuring from a health physics perspective, but they do not adequately address the more fundamental gamma-ray flux effects needed for analysis or characterization purposes. For instance, MicroShield computes gamma photon fluxes both with and without buildup, but these are only available as special printouts. And these can be misleading depending on how gamma-ray energies are grouped when entering their activities into MicroShield. Also, since there is no quantitative information available on how the buildup as a function of gamma energy affects the scattered distribution, verifying the amount of buildup that will be seen by any given detector is difficult. Since a detection system for screening materials may not respond to scattered gamma rays below a certain energy, knowing what the buildup is as a function of energy is useful in determining screening sensitivity.

However these shortcomings are not serious for some applications. Indeed, the calculational results of MicroShield are used by the vendor in a separate waste characterization software package, which uses a dose-to-curie method to infer the contents of specific containers based on a specified distribution of radionuclides. ${ }^{14}$ The ability of MCNP to better predict gamma-ray fluxes in three dimensions for germanium detector measurements of small and large objects was reported by Bronson and Wang ${ }^{15}$, and is now the basis for an expensive, specialized commercial assay tool for in-situ work. Using a simpler, more familiar, and readily available code like MicroShield in place of MCNP is the logical next step in expanding the methods available for waste characterization and material classification screening. 
WSRC-TR-97-00372

Revision 0

\section{ENTERING INPUT DATA AND USING MICROSHIELD}

MicroShield is menu-driven code designed for operation on personal computers with DOS operating software. Upon startup a main menu is presented with options for performing all input, calculations, and output functions. The "New Case - Clear Memory" item is the normal starting point. This option allows the user to select any of 16 geometries for all necessary dimensional inputs: source dimensions, dose point location, and dimensions of multiple shields. Sources and shields can consist of any of 12 common standard materials (i.e. air, water, concrete, aluminum, steel, lead) or custom materials can be input instead. Selection options for all input variables are such that almost any measurement scenario can be adequately modeled and solved for gamma flux predictions.

After entry of the source and shield materials, the radiological aspects of the source are specified. While the code's isotope library may be used to input individual source radionuclides, this can lead to problems with the inclusions of many low energy $x$-ray lines which usually are of no interest or consequence for analytical applications. Also, MicroShield will accept only up to 25 discrete energy gamma rays before it forces entries into its standard energy groups. When this happens, photo-peak information is lost and comparison to flux measurements is impractical. Instead, the user should specify the "New user specified activity and energies" option. Up to 25 discrete entries of energy-activity pairs may be made. This is usually more than enough, if weaker source lines are eliminated or later added in as a separate case. MicroShield automatically converts total activity entries into activity concentrations based on the source dimensions.

The user next must specify the "Buildup Factor Reference Shield". Possible choices are: source, transition, air gap, or one of the shields. In general, the best choice is either the last shield before the dose point, or the air gap. The selection made by the user affects only the magnitude of the buildup factor used in the flux equation above, and ultimately the size of the predicted dose. As the dose is unimportant for most analytical applications, selection of one reference shield over another is of little significance.

Next the user is prompted about the "Integration Parameters" to be used to solve the flux equation. Except in unusual cases where the dose point is quite close to the source, or is offset significantly from the axial center of the source, the default parameters will give good results. If the user is unsure, the defaults can be changed to examine the effects. A convergence to a relatively constant value indicates adequacy of the parameter selections.

A "Case Title" may be entered as a description of up to 60 characters, which is included on all outputs selected for printing. At this point the case is normally solved by selection of the "Run the Case in Memory" menu option. Afterwards the user may assign a DOS file name for the case and save it. Using the DOS file name, the case can be loaded 
WSRC-TR-97-00372

Revision 0

back into memory and modified if desired. All or any of the inputs can be changed and then rerun to examine the effects on the output variable of concern.

After a case is run, the "Print" option may be run to obtain a printout. This gives a useful summary of all the input data, but the results printed here are dose rate information of interest primarily to the health physicist. The "Display" menu option provides a much more useful selection of printouts for analytical applications. These include: "Geometry Dimensions" pictorially; "Material Densities" for the source and shields; "Source Nuclides"; "Buildup Reference Material and Factors"; "Integration Parameters"; "Linear Attenuation Coefficients"; and finally the "Photon Source" data which gives the individual gamma fluxes (called fluence rates in MicroShield) with and without buildup.

The individual gamma fluxes without buildup and the total gamma flux with buildup are measurable quantities which can be verified by germanium detector gamma-ray spectrometry. By verifying MicroShield predictions for some standard geometries, the code can, with some confidence, be applied to many practical situations as follows.

\section{VALIDATION OF MICROSHIELD USING SUITABLE STANDARD SOURCES}

The MicroShield computer code is designed to handle a wide variety of sources, geometries, shields, and conditions. Testing or verifying them all is impossible. Instead, the approach for such codes is to perform a limited number of real source measurements against the code's modeling predictions, and to also thoroughly exercise the code's algorithms and coding under a suitable software quality assurance program. As to the latter, a vendor's verification and validation report implemented in accordance with requirements of $10 \mathrm{CRF} 50$ Appendix $B$ is documented. ${ }^{16}$

The sources use for verification by the former approach are described in Table A1

Table A1. Description of Sources Used for MicroShield Flux Comparisons

\begin{tabular}{|c|c|c|c|c|}
\hline 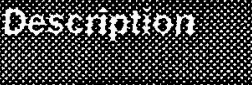 & $\operatorname{lochon}$ & 67 & 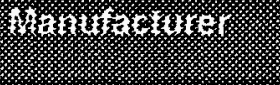 & 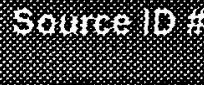 \\
\hline Point: & Eu-152 & & Isotope Products & $482-40-4$ \\
\hline $2 \mathrm{~L}$ Marinelii & $\mathrm{Am}-241, \mathrm{Cs}-137, \mathrm{Co}-60$ & $16.5 \times 14$ & Isotope Products & $479-16-2$ \\
\hline $1 \mathrm{~L}$ Marinelli & $A m-241, C s-137$, Co-60 & $15.2 \times 11.4$ & Analytics & 42686-121 \\
\hline $0.5 \mathrm{~L}$ Marinelli & $\mathrm{Am}-241, \mathrm{Cs}-137, \mathrm{Co}-60$ & $8.89 \times 11.4$ & Analytics & 42689-121 \\
\hline Disk & Am-241, Cs-137, Co-60 & 6.6 & Analytics & 42684-121 \\
\hline 3cc Cylinder & $\mathrm{Am}-241, \mathrm{Cs}-137, \mathrm{Co}-60$ & $0.3 \times 3.2$ & Isotope Products & $479-16-1$ \\
\hline 30 cc Cylinder & $\mathrm{Am}-241, \mathrm{Cs}-137, \mathrm{Co}-60$ & $3.8 \times 3.2$ & Isotope Products & 479-14-3 \\
\hline $9.6 c c$ Cylinder & $\mathrm{Am}-241, \mathrm{Cs}-137, \mathrm{Co}-60$ & $0.3 \times 6.4$ & Isotope Products & $479-14-2$ \\
\hline $96 \mathrm{cc}$ Cylinder & $\mathrm{Am}-241, \mathrm{Cs}-137, \mathrm{Co}-60$ & $3.0 \times 6.4$ & Isotope Products & $479-13-3$ \\
\hline $235 \mathrm{cc}$ Cylinder & $\mathrm{Am}-241, \mathrm{Cs}-137, \mathrm{Co}-60$ & $7.3 \times 6.4$ & Isotope Products & $479-13-1$ \\
\hline
\end{tabular}

Measurements versus MicroShield predictions were performed using ten NISTtraceable standards in eleven geometries. The Marinelli Beakers were modeled in MicroShield as the sum of two geometries: a solid cylinder atop an annular cylinder, as 
shown in Figure A1. All the annular cylinder sections of the Marinellis have standard $(8.26 \mathrm{~cm})$ holes. All the cylinders were modeled as side-views, except the $235 \mathrm{cc}$ cylinder, which was modeled both from the side and an end.

Figure A1. Side View of Marinelli Beaker Counting Arrangement

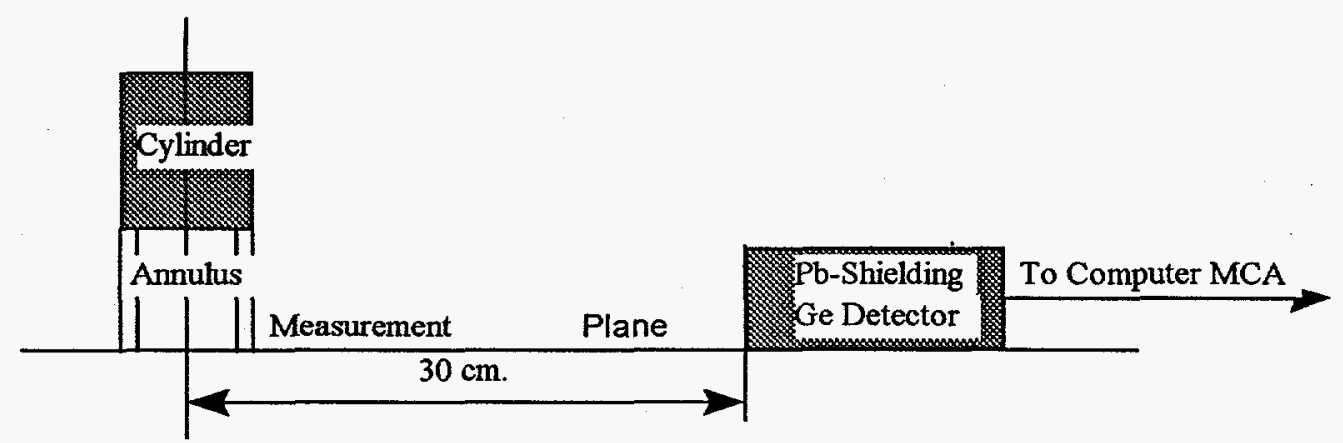

For the side view of cylinders, the measurement distance in all cases was $30 \mathrm{~cm}$ from the cylinder axis. The bottom edge of the germanium detector end-cap $(7.0 \mathrm{~cm}$ diameter) was on the same plane as the source for all measurements. The detector was also shielded on three sides with $5 \mathrm{~cm}$ of lead so that it approximated a two dimensional detector. For the $235 \mathrm{cc}$ cylinder end view, the $30-\mathrm{cm}$ distance is measured from the bottom (farthest) end parallel to the face of the detector end-cap. The disk face was axially centered $30 \mathrm{~cm}$ from the end-cap. The Eu-152 point source was used to compare MicroShield predicted gamma-ray attenuations through different shields and at multiple energies spanning a range up to $1400 \mathrm{keV}$.

The source nuclides were mixed with an epoxy-like material and then poured into the various containers in making the vendor-supplied volume sources. For the disk, nuclides were deposited on a glass-fiber filter taped into a holder. The volume sources all had a density of about $1-1.15 \mathrm{~g} / \mathrm{cc}$ and were modeled as water for the source material.

Each source was decay corrected to $8 / 1 / 97$, which is within 60 days of when all the measurements were completed. In all cases, the source strength was entered as discrete photon energies and activities. This prevented MicroShield from using its standard energy regions, which would result in a loss of discrete gamma-ray information. The volume sources all contained gamma activities ranging from about $1000-2000 \mathrm{\gamma} / \mathrm{s}$ at $60 \mathrm{keV}$, and 2000-6000 $\mathrm{\gamma} / \mathrm{s}$ at the 662,1173 , and $1332 \mathrm{keV}$ lines.

The gamma fluxes from MicroShield cannot be conveniently measured directly, because the detector's absolute efficiency depends on photon energy and the solidangle subtended at the source by the detector, which is difficult to measure or 
WSRC-TR-97-00372

Revision 0

calculate. Instead, the predicted gamma fluxes must be related to the measurable photopeak rates. This is done by comparing the predicted fluxes for some nonattenuating source, such as a point or a disk, at a fixed distance, to the measured peak intensities. Because the disk source contains the principle three gamma-emitting contaminants likely at SRS (Am-241, Cs-137, and Co-60), it was used as the reference for most of the other geometries. Comparing the predicted fluxes for the disk to the four measured photopeak rates for these nuclides, "conversion factors" were determined and used for converting fluxes to peak rates for the other nine volume-source geometries (see Table A2).

Table A2 lists the various measured and predicted parameters and comparisons at each gamma energy for each of the volume sources. The 50-1350 keV energy was selected as an appropriate region of interest for assessing buildup. The measured values in it represent the rate of all counts in the region, less background. The rate is proportional to the absolute efficiency of the detector for all scattered and unscattered gamma interactions, and can be compared to the total "with buildup" gamma flux calculated from MicroShield through a measured conversion factor like those above.

Agreement between the measured and predicted rates for the four discrete energies is quite good for all the sources. Uncertainties $(3 \sigma)$ for $60 \mathrm{keV}$ lines are somewhat large because of the large background presented by the higher energy gamma activities in these sources. Also, the $235 \mathrm{cc}$ end cylinder measurement suffers from the large distance variance posed by this case. But it is clear that MicroShield does a very respectable job of calculating uncollided fluxes of gamma rays under the stated measurement conditions. Agreement for the collided flux (50-1350 keV values) is not as good, but is still acceptable (10-20\%). This is to be expected as buildup values are empirical in nature, whereas photopeak attenuation can be calculated analytically.

The quality of photopeak attenuation calculations was further tested over other energies and more extreme shielding conditions using the Eu-152 point source. These data are shown in Table A3. Three common materials expected to offer significant shielding are aluminum, steel, and lead, and these were the shield materials selected for the point source test.

Just as in Table A2, reference conversion factors were calculated by first measuring the source without any shielding. Nine of Eu-152's more intense gamma rays were selected for comparison with the MicroShield calculations. Again, an appropriate region of interest was selected for the buildup comparison. Here, depending on the particular shield some of the low-energy, weaker lines were not observable. The source-todetector distance for these measurements was $10 \mathrm{~cm}$ instead of the $30 \mathrm{~cm}$ for the previous measurements. Rate comparisons are just as good as those in Table A2. 
Table A2. Comparison of Measured and MicroShield-Modeled Rates

\begin{tabular}{|c|c|c|c|c|c|c|c|}
\hline $\sin (1+1)$ & 稵 & 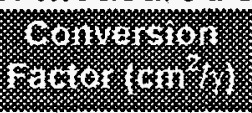 & 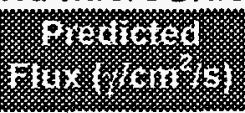 & 20 & 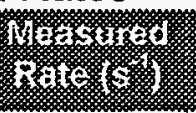 & 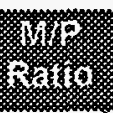 & rit. \\
\hline \multirow[t]{5}{*}{$2 \mathrm{~L}$ Beaker } & 60 & 4.13 & $4.94 \mathrm{E}-02$ & $2.04 \mathrm{E}-01$ & $1.90 \mathrm{E}-01$ & 0.93 & 0.38 \\
\hline & 662 & 4.76 & $3.44 \mathrm{E}-01$ & $1.64 \mathrm{E}+00$ & $1.56 \mathrm{E}+00$ & 0.95 & 0.10 \\
\hline & 1173 & 2.95 & 3.99E-01 & $1.18 \mathrm{E}+00$ & $1.12 E+00$ & 0.95 & 0.10 \\
\hline & 1332 & 2.65 & 3.57E-01 & $9.46 \mathrm{E}-01$ & $1.05 \mathrm{E}+00$ & 1.11 & 0.11 \\
\hline & $50-1350$ & 21 & $1.65 \mathrm{E}+00$ & $3.47 \mathrm{E}+01$ & $3.40 E+01$ & 0.98 & 0.06 \\
\hline \multirow[t]{5}{*}{$1 \mathrm{~L}$ Beaker } & 60 & 4.13 & $8.74 E-02$ & 3.31E-01 & 3.57E-01 & 1.08 & 0.28 \\
\hline & 662 & 4.76 & $1.73 E-01$ & $8.53 E-01$ & $8.49 E-01$ & 0.99 & 0.12 \\
\hline & 1173 & 2.95 & $1.71 \mathrm{E}-01$ & 5.44E-01 & $5.21 E-01$ & 0.96 & 0.12 \\
\hline & 1332 & 2.65 & $1.73 E-01$ & 4.58E-01 & 4.63E-01 & 1.01 & 0.12 \\
\hline & $50-1350$ & 21 & $9.10 \mathrm{E}-01$ & $1.91 E+01$ & $1.56 \mathrm{E}+01$ & 0.82 & 0.05 \\
\hline \multirow[t]{5}{*}{$.5 \mathrm{~L} \mathrm{Beaker}$} & 60 & 4.13 & $7.62 E-02$ & $3.15 E-01$ & $2.86 E-01$ & 0.91 & 0.26 \\
\hline & 662 & 4.76 & $1.40 \mathrm{E}-01$ & $6.68 \mathrm{E}-01$ & $6.31 E-01$ & 0.94 & 0.12 \\
\hline & 1173 & 2.95 & $1.34 \mathrm{E}-01$ & $3.94 \mathrm{E}-01$ & $3.97 E-01$ & 1.01 & 0.15 \\
\hline & 1332 & 2.65 & 1.36E-01 & $3.60 \mathrm{E}-01$ & $3.44 E-01$ & 0.96 & 0.12 \\
\hline & $50-1350$ & 21 & $6.55 \mathrm{E}-01$ & $1.38 \mathrm{E}+01$ & $1.17 E+01$ & 0.85 & 0.06 \\
\hline \multirow[t]{5}{*}{$3 c c$ Cylinder } & 60 & 4.13 & $7.49 \mathrm{E}-02$ & $3.09 \mathrm{E}-01$ & $3.08 \mathrm{E}-01$ & 1.00 & 0.25 \\
\hline & 662 & 4.76 & $4.28 \mathrm{E}-01$ & $2.04 E+00$ & $1.94 E+00$ & 0.95 & 0.09 \\
\hline & 1173 & 2.95 & 4.67E-01 & $1.38 \mathrm{E}+00$ & $1.33 E+00$ & 0.97 & 0.10 \\
\hline & 1332 & 2.65 & $4.70 E-01$ & $1.25 \mathrm{E}+00$ & $1.24 \mathrm{E}+00$ & 0.99 & 0.09 \\
\hline & $50-1350$ & 21 & $1.65 \mathrm{E}+00$ & $3.47 \mathrm{E}+01$ & $3.08 \mathrm{E}+01$ & 0.89 & 0.05 \\
\hline \multirow[t]{5}{*}{$30 \mathrm{cc}$ Cylinder } & 60 & 4.13 & $8.37 E-02$ & $3.46 \mathrm{E}-01$ & $3.53 E-01$ & 1.02 & 0.26 \\
\hline & 662 & 4.76 & $4.42 E-01$ & $2.10 \mathrm{E}+00$ & $1.91 \mathrm{E}+00$ & 0.91 & 0.09 \\
\hline & 1173 & 2.95 & $4.59 E-01$ & $1.35 \mathrm{E}+00$ & $1.30 \mathrm{E}+00$ & 0.96 & 0.11 \\
\hline & 1332 & 2.65 & $4.62 E-01$ & $1.22 E+00$ & $1.18 E+00$ & 0.97 & 0.09 \\
\hline & $50-1350$ & 21 & $1.67 \mathrm{E}+00$ & $3.51 E+01$ & $3.11 \mathrm{E}+01$ & 0.89 & 0.05 \\
\hline \multirow[t]{5}{*}{$9.6 \mathrm{cc}$ Cylinder } & 60 & 4.13 & $6.43 E-02$ & $2.66 \mathrm{E}-01$ & $3.06 \mathrm{E}-01$ & 1.15 & 0.32 \\
\hline & 662 & 4.76 & 4.03E-01 & $1.92 E+00$ & $1.83 E+00$ & 0.95 & 0.09 \\
\hline & 1173 & 2.95 & $4.49 \mathrm{E}-01$ & $1.32 E+00$ & $1.27 E+00$ & 0.96 & 0.10 \\
\hline & 1332 & 2.65 & $4.53 E-01$ & $1.20 \mathrm{E}+00$ & $1.19 \mathrm{E}+00$ & 0.99 & 0.09 \\
\hline & $50-1350$ & 21 & $1.72 \mathrm{E}+00$ & $3.61 \mathrm{E}+01$ & $3.10 \mathrm{E}+01$ & 0.86 & 0.05 \\
\hline \multirow[t]{5}{*}{ 96cc Cylinder } & 60 & 4.13 & $6.83 E-02$ & $2.82 E-01$ & $3.19 \mathrm{E}-01$ & 1.13 & 0.31 \\
\hline & 662 & 4.76 & $4.18 E-01$ & $1.99 \mathrm{E}+00$ & $1.87 E+00$ & 0.94 & 0.09 \\
\hline & 1173 & 2.95 & 4.67E-01 & $1.38 E+00$ & $1.29 E+00$ & 0.94 & 0.10 \\
\hline & 1332 & 2.65 & $4.72 \mathrm{E}-01$ & $1.25 \mathrm{E}+00$ & $1.14 \mathrm{E}+00$ & 0.91 & 0.09 \\
\hline & $50-1350$ & 21 & $1.79 \mathrm{E}+00$ & $3.76 \mathrm{E}+01$ & $3.44 E+01$ & 0.92 & 0.05 \\
\hline \multirow[t]{5}{*}{235 cc Cylinder } & 60 & 4.13 & $6.33 E-02$ & $2.61 E-01$ & $2.65 E-01$ & 1.01 & 0.31 \\
\hline & 662 & 4.76 & $4.01 E-01$ & $1.91 \mathrm{E}+00$ & $1.79 \mathrm{E}+00$ & 0.94 & 0.09 \\
\hline & 1173 & 2.95 & 4.47E-01 & $1.32 \mathrm{E}+00$ & $1.21 \mathrm{E}+00$ & 0.92 & 0.10 \\
\hline & 1332 & 2.65 & $4.52 E-01$ & $1.20 \mathrm{E}+00$ & $1.14 \mathrm{E}+00$ & 0.95 & 0.09 \\
\hline & $50-1350$ & 21 & $1.72 E+00$ & $3.61 \mathrm{E}+01$ & $3.34 E+01$ & 0.92 & 0.05 \\
\hline \multirow[t]{5}{*}{$235 \mathrm{cc}$ End Cyl. } & 60 & 4.13 & $7.59 E-02$ & $3.13 E-01$ & $3.03 E-01$ & 0.97 & 0.27 \\
\hline & 662 & 4.76 & 5.05E-01 & $2.40 \mathrm{E}+00$ & $2.09 E+00$ & 0.87 & 0.09 \\
\hline & 1173 & 2.95 & $5.69 E-01$ & $1.68 \mathrm{E}+00$ & $1.48 \mathrm{E}+00$ & 0.88 & 0.09 \\
\hline & 1332 & 2.65 & $5.77 \mathrm{E}-01$ & $1.53 E+00$ & $1.36 \mathrm{E}+00$ & 0.89 & 0.08 \\
\hline & $50-1350$ & 21 & $2.26 \mathrm{E}+00$ & $4.75 E+01$ & $3.77 \mathrm{E}+01$ & 0.79 & 0.05 \\
\hline
\end{tabular}


Table A3. Comparison of Measured and MicroShield-Modeled Rates for Eu-152

\begin{tabular}{|c|c|c|c|c|c|c|c|}
\hline Evistis & $=0$ & 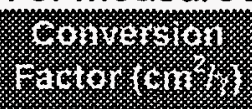 & 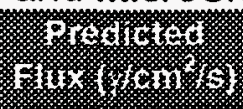 & 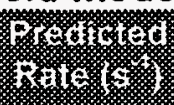 & 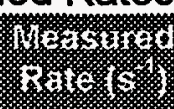 & Sisto & 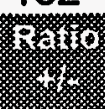 \\
\hline \multirow{10}{*}{$0.129 \mathrm{~cm} \mathrm{~Pb}$} & 122 & 8.46 & $2.15 \mathrm{E}-02$ & $1.82 \mathrm{E}-01$ & & & \\
\hline & 245 & 6.35 & $6.78 \mathrm{E}-01$ & $4.30 \mathrm{E}+00$ & $4.00 E+00$ & 0.93 & 0.15 \\
\hline & 344 & 4.88 & $4.13 E+00$ & $2.01 E+01$ & $1.95 \mathrm{E}+01$ & 0.97 & 0.05 \\
\hline & 444 & 4.08 & $5.84 \mathrm{E}-01$ & $2.38 \mathrm{E}+00$ & $2.16 \mathrm{E}+00$ & 0.91 & 0.21 \\
\hline & 779 & 2.52 & $2.84 E+00$ & $7.15 \mathrm{E}+00$ & $7.33 E+00$ & 1.02 & 0.11 \\
\hline & 964 & 2.04 & $3.32 \mathrm{E}+00$ & $6.76 E+00$ & $6.80 \mathrm{E}+00$ & 1.01 & 0.10 \\
\hline & 1086 & 2.03 & $2.32 E+00$ & $4.70 E+00$ & $4.53 E+\infty 0$ & 0.96 & 0.14 \\
\hline & 1112 & 1.93 & $3.10 \mathrm{E}+00$ & $5.98 \mathrm{E}+00$ & $5.93 E+00$ & 0.99 & 0.11 \\
\hline & 1408 & 1.55 & $4.92 E+00$ & $7.62 \mathrm{E}+00$ & $7.33 E+00$ & 0.96 & 0.09 \\
\hline & $53-1985$ & 16.44 & $3.19 \mathrm{E}+01$ & $5.24 \mathrm{E}+02$ & $4.35 \mathrm{E}+02$ & 0.83 & 0.01 \\
\hline \multirow[t]{10}{*}{$1.905 \mathrm{~cm} \mathrm{Al}$} & 122 & 8.46 & $3.50 \mathrm{E}+00$ & $2.96 \mathrm{E}+01$ & $2.99 E+01$ & 1.01 & 0.05 \\
\hline & 245 & 6.35 & $1.10 E+00$ & $7.00 E+00$ & $6.40 E+00$ & 0.91 & 0.11 \\
\hline & 344 & 4.88 & $4.18 \mathrm{E}+00$ & $2.04 \mathrm{E}+01$ & $1.97 \mathrm{E}+01$ & 0.97 & 0.05 \\
\hline & 444 & 4.08 & $5.15 \mathrm{E}-01$ & $2.10 \mathrm{E}+00$ & $2.08 \mathrm{E}+00$ & 0.99 & 0.25 \\
\hline & 779 & 2.52 & $2.33 E+00$ & $5.87 \mathrm{E}+00$ & $5.43 \mathrm{E}+00$ & 0.93 & 0.11 \\
\hline & 964 & 2.04 & $2.73 E+00$ & $5.57 \mathrm{E}+00$ & $5.63 E+00$ & 1.01 & 0.11 \\
\hline & 1086 & 2.03 & $1.92 \mathrm{E}+00$ & $3.90 \mathrm{E}+00$ & $3.67 \mathrm{E}+00$ & 0.94 & 0.14 \\
\hline & 1112 & 1.93 & $2.57 \mathrm{E}+00$ & $4.96 \mathrm{E}+00$ & $5.03 E+00$ & 1.01 & 0.12 \\
\hline & 1408 & 1.55 & $4.15 E+00$ & $6.43 \mathrm{E}+00$ & $6.33 E+00$ & 0.98 & 0.09 \\
\hline & $53-1985$ & 16.44 & $4.02 E+01$ & $6.60 \mathrm{E}+02$ & $5.63 E+02$ & 0.85 & 0.01 \\
\hline \multirow[t]{10}{*}{$5.08 \mathrm{~cm} \mathrm{SS}$} & 122 & 8.46 & $4.27 \mathrm{E}-04$ & $3.61 \mathrm{E}-03$ & & & \\
\hline & 245 & 6.35 & $1.50 \mathrm{E}-02$ & $9.53 \mathrm{E}-02$ & & & \\
\hline & 344 & 4.88 & $1.23 \mathrm{E}-01$ & $5.98 \mathrm{E}-01$ & $6.58 \mathrm{E}-01$ & 1.10 & 0.17 \\
\hline & 444 & 4.08 & $2.29 \mathrm{E}-02$ & $9.34 \mathrm{E}-02$ & & & \\
\hline & 779 & 2.52 & $2.14 \mathrm{E}-01$ & $5.39 \mathrm{E}-01$ & $5.17 E-01$ & 0.96 & 0.13 \\
\hline & 964 & 2.04 & $3.18 \mathrm{E}-01$ & $6.48 \mathrm{E}-01$ & $6.67 \mathrm{E}-01$ & 1.03 & 0.14 \\
\hline & 1086 & 2.03 & $2.53 \mathrm{E}-01$ & $5.13 \mathrm{E}-01$ & $4.83 \mathrm{E}-01$ & 0.94 & 0.14 \\
\hline & 1112 & 1.93 & $3.47 E-01$ & $6.69 \mathrm{E}-01$ & $6.69 \mathrm{E}-01$ & 1.00 & 0.11 \\
\hline & 1408 & 1.55 & $7.00 \mathrm{E}-01$ & $1.09 \mathrm{E}+00$ & $1.11 \mathrm{E}+00$ & 1.02 & 0.08 \\
\hline & 53-1985 & 16.44 & $1.09 \mathrm{E}+01$ & $1.80 \mathrm{E}+02$ & $1.84 \mathrm{E}+02$ & 1.02 & 0.01 \\
\hline
\end{tabular}

Results in Tables A2 and A3 are proof of MicroShield's ability to yield good analytical predictions under a variety of source geometries and shielding conditions. Testing over more extremes in conditions would offer further assurance, but this is impractical to do with NIST-traceable sources, which are limited in size, activity, and availability. Indeed, there is a preponderance of evidence here and for the many test cases illustrated in Reference 16, the verification and validation document, suggesting further comparison would likely be measurement-limited and of little use. The solution algorithms in MicroShield are time-tested and recognized as sound ways to model and calculationally solve complex problems from first principles. And they have been extensively verified through dose and shielding calculations performed over many years of use in commercial applications. 


\section{REFERENCES}

1. "Savannah River Site Low-Level Waste Treatment and Disposal Flowsheet", prepared for WSRC Solid Waste Management Department by H\&R Technical Associates, Inc.,P.O. Box 4159 Oak Ridge, TN 37831-4159, November 1996

2. R.G. Jaeger et.al., Engineering Compendium On Radiation Shielding, SpringerVerlag, New York, 1968.

3. A.B. Chilton et.al., Principles Of Radiation Shielding, Prentice-Hall, Englewood Cliffs, N.J., 1984.

4. R.L. Engle et.al., "ISOSHLD, A Computer Code For General Purpose Shielding Analysis", U.S. Department of Energy (BNWL-2316), 1966.

5. MicroShield ${ }^{\text {TM }}$ Version 4.21, Grove Engineering, Inc., 15215 Shady Grove Road, Rockville, MD 20850.

6. U.S. Department of Energy, "Radioactive Waste Management", Order 5820.2A, (1988).

7. Procedure 517,Rev.0, "Radiological Release of Material", Radiation and Contamination Control Procedures, Manual 5Q1.1, Westinghouse Savannah River Company, April, 1997.

8. WM-2100 Series $Q^{2}$ Low-Level Waste Assay System and In Situ Object Counting System (ISOCS), Canberra Industries Inc., 800 Research Parkway, Meriden, CT 06450

9. R. C. Hochel, "Automated Radiological Scanning of Potentially Contaminated Railroad Crossties for Free Release or Disposal", Report WSRC-TR-96-0176, Rev.1, Westinghouse Savannah River Company, (1996).

10. R. C. Hochel, "The Characterization of Activation Product Radionuclides in Reactor Scrap Metals", Report WSRC-TR-97-0168, Rev.0, Westinghouse Savannah River Company, (1997).

11. J.F. Briesmeister, MCNP-A General Monte Carlo N-Particle Transport Code, Version 4a. Report LA-12625-M, Los Alamos National Laboratory, November 1993.

12. American Nuclear Society, "American National Standard for Calculation and Measurement of Direct and Scattered Gamma Radiation from LWR Nuclear Power Plants", (ANSI/ANS 6.6.1-1979), 1979. 
13. European Shielding Information Service, "Specification for Gamma Ray Shielding Benchmark Applicable to a Nuclear Radioactive Waste Facility", (1981).

14. MicroWasteChar ${ }^{\mathrm{T} M}$ Version 2.0, Grove Engineering, Inc., 15215 Shady Grove Road, Rockville, MD 20850.

15. F.L. Bronson and L. Wang, "Validation of the MCNP Monte Carlo Code for Germanium Detector Gamma Efficiency Calibrations", Proceedings of Waste Management 96, Tucson, AZ, Feb. 1996.

16. MicroShield Version 4 Verification \& Validation Report, Revision 4, Grove Engineering; Inc., 15215 Shady Grove Road, Rockville, MD 20850, GEI MS-0002, Oct. 15, 1994 